\title{
Highly efficient supercapacitor using single-walled carbon nanotube electrodes and ionic liquid incorporated solid gel electrolyte
}

High Performance Polymers 2018, Vol. 30(8) 971-977

(C) The Author(s) 2018 Article reuse guidelines: sagepub.com/journals-permissions DOI: $10.1177 / 0954008318772333$ journals.sagepub.com/home/hip

(S)AGE

\author{
Shirin Siyahjani ', Saliha Oner ${ }^{1,2}$, Pramod K Singh ${ }^{1,3}$ \\ and Canan Varlikli ${ }^{1,4}$
}

\begin{abstract}
Gel polymer electrolyte (GPE) comprising a low viscosity ionic liquid, that is, I-propyl-3-methyl imidazolium bis(trifluoromethyl sulfonyl)imide (PMI-TFSI, viscosity $38 \mathrm{cP}$ at $20^{\circ} \mathrm{C}$ ) and a polymer, that is, polyvinyl alcohol (PVA) have been prepared using solution cast technique and characterized by impedance spectroscopy, X-ray diffraction, differential scanning calorimetry, optical microscopy, and Fourier transform infrared spectroscopy. Blending PMI-TFSI with PVA matrix hindered the crystallinity of polymer matrix and presented remarkable enhancement in electrical conductivity with a conductivity maxima at 250 wt\% PMI-TFSI. The prepared electric double-layer capacitor using single-walled carbon nanotube as symmetric electrodes and PVA:250 wt\% PMI-TFSI as GPE presented a capacitance value of about $28 \mathrm{~F} \mathrm{~g}^{-1}$.
\end{abstract}

\section{Keywords}

SWCNT, gel polymer electrolyte, XRD, DSC, supercapacitor

\section{Introduction}

Fuel cells, batteries, and supercapacitors are typical nonconventional energy devices based on the principle of electrochemical energy conversion. These devices convert the chemical energy into electrical energy by means of electrochemical reactions. ${ }^{1-3}$ Supercapacitors or electrochemical supercapacitors (ESs) are energy storage devices that combine the high energy storage capability of batteries with the high power delivery capability of the capacitors. These capacitors can be used as power backup in a wide range of applications such as hybrid electric vehicles (HEVs), portable electronics, medical electronics, and military devices. ${ }^{4-7}$ Depending on the charge storage mechanism, ESs can be classified into three categories: (i) electric double-layer capacitors (EDLCs), where the capacitance is produced by the electrostatic charge separation at the interface between the electrode and the electrolyte; (ii) pseudocapacitors, which rely on fast and reversible faradaic redox reactions to store the charges; and (iii) hybrid ESs, which refer to the ones using both the EDLC and faradic mechanisms to store charges. In this article, we focus our attention toward EDLC using gel polymer electrolyte (GPE). An EDLC comprises a structure where electrolyte is sandwiched between symmetric or unsymmetric electrodes. The maximum energy $\left(E_{\max }\right)$ and power $\left(P_{\max }\right)$ of EDLC is strongly dependent on both electrode and electrolyte materials. Porous carbon materials such as activated carbon, porous carbon, carbide-derived carbon, carbon aerogels, onion-like carbon, carbon nanotubes (CNTs), carbon shell graphene, and graphene quantum dots are playing a significant role in developing efficient EDLC. ${ }^{8-13}$ As an active material, CNTs,

\footnotetext{
' Solar Energy Institute, Ege University, Bornova, Izmir, Turkey

${ }^{2}$ Dyo Boya Fab. San. Tic. A.Ş., AOSB Çiğli, Izmir, Turkey

${ }^{3}$ Department of Physics, Sharda University, Greater Noida, Uttar Pradesh, India

${ }^{4}$ Department of Photonics, Izmir Institute of Technology, Urla, Izmir, Turkey
}

\section{Corresponding authors:}

Pramod K Singh, Solar Energy Institute, Ege University, 35100 Bornova, Izmir, Turkey; Department of Physics, Sharda University, Greater Noida 201310, Uttar Pradesh, India.

Canan Varlikli, Ege University, Solar Energy Institute, 35I00 Bornova, Izmir, Turkey; Department of Photonics, Izmir Institute of Technology, 35430 Urla, Izmir, Turkey.

Emails: pramodkumar.singh@sharda.ac.in; cananvarlikli@iyte.edu.tr 
especially the single-walled carbon nanotube (SWCNT), has excellent properties such as high surface area, high conductivity, regular pore structures, high flexibility, and electrochemical stability. ${ }^{14,15}$ The current employed electrolytes in commercial EDLC include aqueous and organic electrolytes. However, due to narrow electrochemical windows of these electrolytes, it is not possible to obtain high energy and power density. ${ }^{16}$ For EDLCs, ionic liquids (ILs) or room-temperature molten salts consisting of organic cation (and anion) are considered as novel alternative electrolyte materials. ILs are solvent-free electrolytes with many suitable properties that make them attractive for electrochemical energy storage such as high chemical and thermal stability, negligible vapor pressure, broad electrochemical stability potential window and an immense parameter space in terms of ion selection and resulting properties. Imidazolium-based salts are the most popular ILs and several salts with the 1-ethyl-3-methylimidazolium cation (EMI), which displays a cathodic stability of $-1.8 \mathrm{~V}$ versus NHE, and with such anions as $\mathrm{BF}_{4}$, $\mathrm{PF}_{6},\left(\mathrm{CF}_{3} \mathrm{SO}_{2}\right)_{2} \mathrm{~N}, \mathrm{CF}_{3} \mathrm{SO}_{3}$, which in turn divergently affect the limit of the anodic window, the melting point and hence the conductivity of the ILs were developed. ${ }^{17-20}$

Polymer electrolytes are widely used in many applications such as solid-state batteries, supercapacitors, and display devices. They have many advantages over liquid electrolytes because of the low cost, flexibility, lightweight, mechanical stability, durability, and corrosionfree properties. Many good polymer electrolytes had been developed before the advent of IL using polar polymers such as poly (propylene oxide) (PPO), poly (ethylene oxide) (PEO), poly (vinylidene fluoride) (PVDF), poly (vinylidene fluoride-co-hexafluoropropylene) PVDFHFP. ${ }^{1,21-23}$ However, the studies based on polyvinyl alcohol (PVA) are insufficient. Hydroxyl groups on PVA assist in the formation of polymer electrolyte. Ion formation occurs due to the dissociation of salt/acid added to the polymer and conduction takes place in the polymer. ${ }^{24} \mathrm{Con}-$ ductivity level of PVA polymer electrolyte is too low at room temperature, which limits its practical applications. In order to increase the ionic conductivity, some plasticizers can be added. However, they degrade the mechanical stability of the polymer electrolyte film. It has been analyzed that the addition of IL to the polymer electrolyte, that is, ionic liquid-incorporated gel polymer electrolytes (ILGPEs) serves as a solid plasticizer and improves the mechanical stability as well as electrical conductivity. ${ }^{25}$

ILGPEs are proposed as substitutes for liquid electrolytes in EDLC due to their many advantageous properties such as high electrical conductivity, wide electrochemical window, low risk of leakage, and formation of proper electrode electrolyte contact. ILGPEs containing polymers such as PVDF-HFP, polymethylmetacrylate (PMMA), polyacrylonitrile (PAN), and many ILs (mostly based on imidazolium-based cation) have been used in EDLC so far. ${ }^{26-29}$ However, studies on EDLC comprising PVAbased ILGPE are limited. Arof and coworkers ${ }^{30}$ have reported an efficient EDLC comprising PVA/ammonium acetate $\left(\mathrm{CH}_{3} \mathrm{COONH}_{4}\right) / 1$-butyl 3-methylimidazolium chloride (BmImCl) IL.

In this article, we have successfully fabricated an EDLC comprising PVA and PMI-TFSIILGPE films and SWCNTbased active symmetric electrodes. The ILGPE films were characterized by electrochemical impedance spectroscopy (EIS), X-ray diffraction (XRD), differential scanning calorimetry (DSC), optical microscopy (OM), and Fourier transform infrared (FTIR) spectroscopy. The performance characteristic of EDLC was evaluated using EIS and cyclic voltammetry $(\mathrm{CV})$.

\section{Experimental details}

\section{Preparation of GPE and EDLC electrodes}

PVA (average molecular weight $\left(M_{\mathrm{W}}\right)$ is about 250,000 $\mathrm{g} / \mathrm{mol}$ ), PVDF-HFP (average $M_{\mathrm{W}}$ is about $400,000 \mathrm{~g} / \mathrm{mol}$ ) and solvents were obtained from Sigma Aldrich (St. Louis, Missouri, USA). A solution-cast method was adopted to prepare the GPE film. The polymer PVA was dissolved in distilled water (DI), and the IL PMI-TFSI was mixed with the PVA/DI solution. The mixture was stirred magnetically overnight, after which it was poured in glass petri dishes, and the DI was allowed to evaporate slowly. Such films of different compositions of PMI-TFSI (PVA: $x$ wt $\%$ PMI-TFSI, where $x=0,40,80,120,170,250,300$ ) were prepared and characterized. Finally, semitransparent freestanding flexible GPE films were obtained and characterized.

SWCNT was purchased from Cheap Tubes Inc. (Grafton, VT, USA). To prepare the electrodes, the SWCNT powder and PVDF-HFP (as a binder) in the ratio of 70:30 $(\mathrm{w} / \mathrm{w})$ were slowly grinded (about $30 \mathrm{~min}$ ) in a mortar and pestle with acetone to form a homogeneous paste. This paste was finally coated on flexible high-density graphite sheets ( $250 \mu \mathrm{m}$ thick, Nickunj Eximp Enterprises, Mumbai, Maharashtra, India). These electrodes were left overnight at room temperature before using them as EDLC electrodes.

\section{Fabrication of EDLC cell}

In order to construct a symmetrical EDLC, the ILGPE (maximum conductivity composition) was coated on the electrodes. Two such electrode/electrolyte systems were stacked over each other and pressed gently such that ILGPE is sandwiched between the two SWCNT electrodes. The final fabricated EDLC was loaded in a sample holder for electrochemical measurements.

\section{Instrumentation}

The electrochemical performances of the GPE films were tested by measuring the ionic conductivity. The ionic 


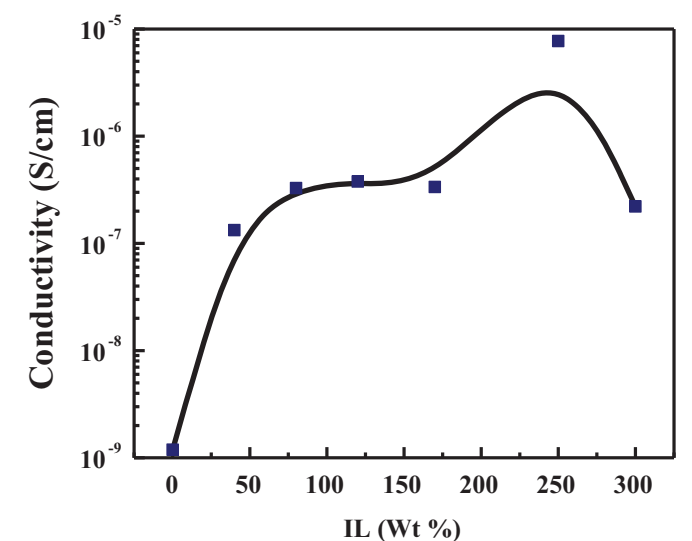

Figure I. lonic conductivity versus composition plot in PVA and PVA: $x$ wt\% IL $(x=0,40,80,120,170,250,300)$ GPE films. PVA: polyvinyl alcohol; GPE: gel polymer electrolyte.

conductivity was evaluated by EIS with a frequency range between $100 \mathrm{~Hz}$ and $100 \mathrm{kHz}$. The impedance spectra of GPE films were recorded by sandwiching them between two stainless steel electrodes using a $\mathrm{CH}$ Instrument $\mathrm{CHI}$ 660B (Bee Cave, Texas, USA). The specific capacitance, $\mathrm{CV}$, and galvano charge-discharge characteristics of EDLC were carried out using the same instrument.

XRD patterns of pure and GPE films were recorded with a Rigaku Ultima IV multipurpose X-ray diffractometer (Tokyo, Japan) using copper $K_{\alpha}$ radiation in the Bragg angle $(2 \theta)$ range from $10^{\circ}$ to $80^{\circ}$ at a scan rate of $2^{\circ} \mathrm{min}^{-1}$.

The FTIR studies of the prepared GPE films of different compositions were carried out using a Perkin Elmer FTIR (Spectrum BX; Waltham, Massachusetts, USA) with the attenuated total reflectance apparatus in the range of $4000-400 \mathrm{~cm}^{-1}$ wave numbers.

DSC measurement of pure and GPE films were recorded using a Perkin Elmer Pyris 6 DSC instrument at a heating rate of $10^{\circ} \mathrm{C} \mathrm{min}^{-1}$ under nitrogen environment, while OMs were taken using Olympus CX31 optic microscope, Pennsylvania USA.

\section{Results and discussion}

\section{lonic conductivity analysis}

The ionic conductivity of pure and ILGPE films at room temperature were evaluated using electrochemical impedance spectroscopy with the following formula,

$$
\sigma=G \frac{l}{A}
$$

where $\sigma$ is the conductivity, $G$ is the conductance of the sample, $l$ is the thickness of the sample, and $A$ is the area of sample in contact. The evaluated ionic conductivity values with varying IL concentrations are shown in Figure 1. It was clear that the ionic conductivity of the pure PVA was very poor $\left(1.19 \times 10^{-9} \mathrm{~S} \mathrm{~cm}^{-1}\right)$. The conductivity of PVA

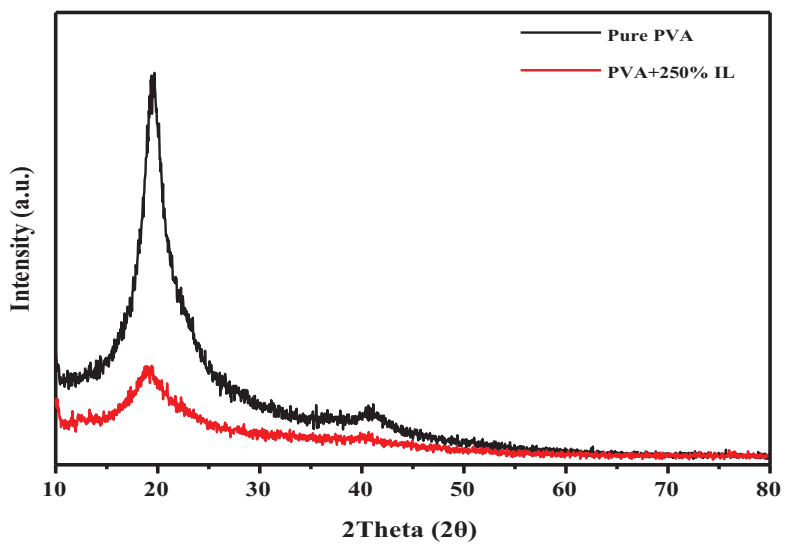

Figure 2. XRD pattern of PVA and PVA:250 wt\% GPE films. $X R D$ : X-ray diffraction; PVA: polyvinyl alcohol; GPE: gel polymer electrolyte.

increases considerably with the increasing amount of IL, attains maxima at $250 \mathrm{wt} \%$ of IL concentration $(7.72 \times$ $10^{-6} \mathrm{~S} \mathrm{~cm}^{-1}$ ), and then decreases. Such types of conductivity behavior are reported in the literature with insulating polymers such as PEO and PVDF-HFP. ${ }^{25,31,32}$ The conductivity in case of ionic materials is governed by the equation.

$$
\sigma=n \cdot q \cdot \mu
$$

where $n$ is the number of charge carriers, $q$ is the coulomb charge, and $\mu$ is the mobility of ions. It was depicted that with increasing IL concentration, the numbers of ionic charge carriers $(n)$ also increase, because IL is solely composed only of ions (imidazolium cations and TFSI anions in the present case), which leads to overall increase in the conductivity. ${ }^{25,31,32}$

\section{Structural and morphological analyses}

To check the change in the morphology of the GPE films by adding IL into PVA polymer matrix, we have recorded the XRD patterns of pure as well as ILGPE films having maximum conductivity. Figure 2 shows the recorded XRD patterns of pure PVA and PVA:250 wt\% IL GPE films. Pure PVA shows well-known semicrystalline peak at $2 \theta=20^{\circ}$ and $40.7^{\circ}$. It was clearly observed that by doping IL into the polymer matrix (PVA), the peak intensity goes down, which is a clear indication of a decrease in the crystallinity of the PVA film and, consequently, the increase in the amorphicity. It is in the literature that amorphous matrix is a conductivityrich region, ${ }^{33}$ and hence, our conductivity increases with IL doping, showing good agreement with our conductivity data.

The crystallinity of the host polymer (PVA) and ILGPE films were further examined by DSC using a TA instrument MDSC 2910 at a heating rate of $10^{\circ} \mathrm{C} \mathrm{min}^{-1}$. The sample weights were maintained in the range of $3-4 \mathrm{mg}$, and all the experiments were performed under nitrogen flow. Figure 3 shows the DSC curves obtained for pure PVA as well as PVA:250 wt\% ILGPE films, and the evaluated parameters 


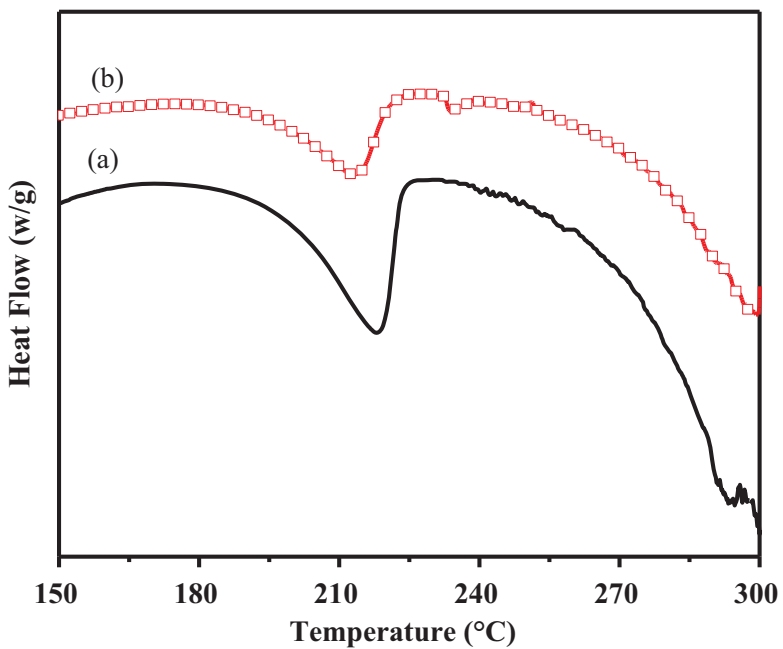

Figure 3. DSC curves of (a) pure PVA and (b) PVA:250 wt\% ILGPE films. DSC: differential scanning calorimetry; PVA: polyvinyl alcohol; ILGPE: ionic liquid-incorporated gel polymer electrolytes.

Table I. Calculated values of $\chi$ along with $T_{\mathrm{m}}$ and corresponding $\Delta H_{\mathrm{f}}$ data of pure PVA and PVA:250 wt\% ILGPE films.

\begin{tabular}{lccc}
\hline System & $T_{\mathrm{m}}\left({ }^{\circ} \mathrm{C}\right)$ & $\Delta H_{\mathrm{f}}\left(\mathrm{g} \mathrm{g}^{-1}\right)$ & $\chi(\%)$ \\
\hline Pure PVA & 218.08 & 76.93 & 55.50 \\
PVA + 250 wt\% IL & 212.86 & 39.34 & 28.38 \\
\hline
\end{tabular}

$\chi$ : percentage crystallinity; $T_{m}$ : melting temperature; $\Delta H_{f}$. heat of fusion; PVA: polyvinyl alcohol; IL: ionic liquid; ILGPE: ionic liquid-incorporated gel polymer electrolytes.

are given in Table 1. Pure PVA shows the heat of fusion $\left(\Delta H_{\mathrm{f}}\right)$ and melting peak temperature $\left(T_{\mathrm{m}}\right)$ at $76.93 \mathrm{~J} \mathrm{~g}^{-1}$ and $218.08^{\circ} \mathrm{C}$, respectively. With the addition of IL, both $\Delta H_{\mathrm{f}}$ and $T_{\mathrm{m}}$ values decreased (Table 1). It has also been observed that the melting endotherm was broadened after the incorporation of the IL (Figure 3). The relative percentage of crystallinity $(\chi)$ has been calculated using the formula $\chi=\Delta H_{\mathrm{f}} / \Delta H_{\mathrm{f} 0}$, assuming $\Delta H_{\mathrm{f} 0}$ of $100 \%$ crystalline PVA film to be $138.60 \mathrm{~J} \mathrm{~g}^{-1} .{ }^{34}$ The calculated values of $\chi$ and $T_{\mathrm{m}}$ are listed in Table 1 . The reduced $T_{\mathrm{m}}$, crystallinity, and the broadening of the melting endotherm supported our findings, which we have already discussed in the XRD section.

To further confirm our observation (reduction in crystallinity by IL doping), we have taken the optical micrographs of pure polymer (PVA) and ILGPE films using optical microscope (Olympus CX31). The obtained photographs are shown in Figure 4. It was observed that pure PVA film (Figure 4(a)) shows plane surface morphology. Adding IL into the polymer matrix shows the appearance of amorphous patches (black portion in spherulites). The amorphous region within the polymer matrix is already known as conductivity-rich regions, and hence, our microscopic study shows good agreement with our XRD and DSC measurements. (a)

(b)
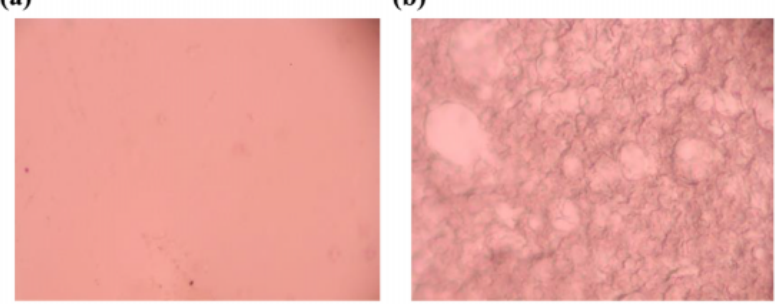

Figure 4. Optical micrographs of (a) pure PVA and (b) PVA:250 wt\% ILGPE films. PVA: polyvinyl alcohol; ILGPE: ionic liquidincorporated gel polymer electrolyte.

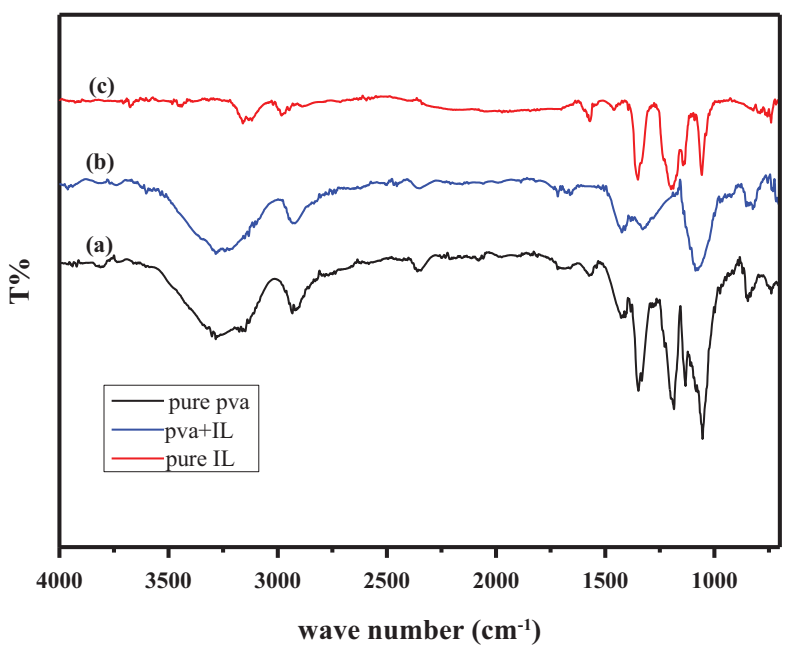

Figure 5. FTIR spectra of (a) pure PVA film, (b) PVA:250 wt\% ILGPE film, and (c) IL. PVA: polyvinyl alcohol; ILGPE: ionic liquidincorporated gel polymer electrolyte; IL: ionic liquid.

IR spectroscopy is an important technique for the investigation of polymer structure, as it provides information about the complexation and interactions between the various constituents in the polymer electrolyte. Figure 5 shows the recorded FTIR spectra of pure PVA film, IL, and ILGPE comprising $250 \mathrm{wt} \%$ IL (maximum conductivity film). Pure PVA film shows prominent peaks at 3283, 2932, 1717, 1426, $1347 \mathrm{~cm}^{-1}$ (Figure 5(a)) corresponding to $\mathrm{O}-\mathrm{H}$ stretching, $\mathrm{C}-\mathrm{H}$ stretching, $\mathrm{C}=\mathrm{O}$ stretching, $\mathrm{C}-\mathrm{H}$ bending and stretching, respectively, while the peaks appear at lower wave numbers, that is, 1132, 1053, 846, $661 \mathrm{~cm}^{-1}$ assigned to $\mathrm{CO}$ bonding, $\mathrm{C}=\mathrm{O}$ stretching, $\mathrm{C}-\mathrm{C}$ stretching, and $\mathrm{OH}$ bending, respectively. For IL, the peaks appear at $3159,2982,1569,1350 \mathrm{~cm}^{-1}$ corresponding to the $\mathrm{C}$-aromatic carbon, $\mathrm{CH}$ stretching, $\mathrm{CH}_{3}(\mathrm{~N})$ stretching, and antisymmetric $\mathrm{SO}_{2}$ stretching. The bonds appear at lower wave numbers such as 1197, 1143, 1057, 740, 614 $\mathrm{cm}^{-1}$ corresponding to cis-TFSI + trans-TFSI (Figure 5(c)). A closed comparison of Figure 5 (a) to (c) revealed that the GPE films doped with IL (Figure 5(b)) do not show any new peak other than pure PVA or IL host, which affirms that polymer doped with IL has not chemically 


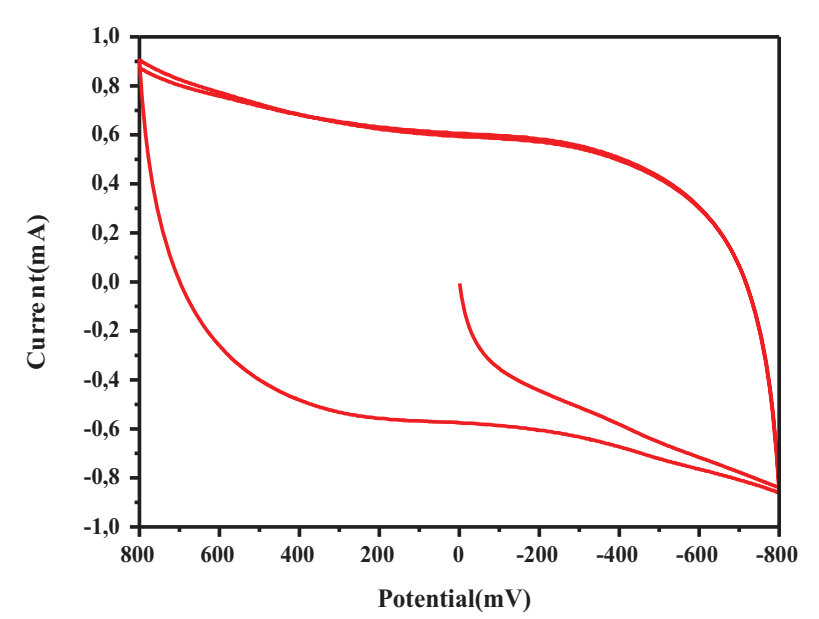

Figure 6. $C V$ of the EDLC using maximum conductivity GPE film and SWCNT electrodes measured at $50 \mathrm{mV} \mathrm{S}^{-1}$ scan rate. CV: cyclic voltammetry; EDLC: electric double-layer capacitor; GPE: gel polymer electrolyte; SWCNT: single-walled carbon nanotube.

reacted (no new compound forms). Additionally, the absorption peaks appear in wave numbers of 2932, 1347, $1053,738 \mathrm{~cm}^{-1}$ in PVA, and peaks of 2982, 1357, 1057, $740 \mathrm{~cm}^{-1}$ in IL are shifted to $2921,1328,1086,731 \mathrm{~cm}^{-1}$ in ILGPE. The shifting of the abovementioned peak positions in ILGPE is possibly due to the interaction of IL with the polymer backbone as reported in the literature. ${ }^{25,35-37}$

\section{EDLC fabrication and performance}

For supercapacitor fabrication, we have adopted the method reported by Hashmi et al. ${ }^{16}$ We have used $1 \times 1$ $\mathrm{cm}^{2}$ graphite sheet as current collector, which was coated with SWCNT paste using polymer (PVDF-HFP) as a binder. The symmetric EDLC comprising maximum conductivity ILGPE sandwiched between electrodes have been fabricated and its performance (capacitance) value is evaluated using $\mathrm{CV}$ and impedance spectroscopy (frequency range $10 \mathrm{mHz}-10 \mathrm{kHz}$ ). Figure 6 shows the $\mathrm{CV}$ curve of fabricated EDLC in the potential range of -0.8 to $0.8 \mathrm{~V}$ at $50 \mathrm{mV} \mathrm{s}^{-1}$ scan rate. The capacitance value was evaluated using the following formula,

$$
C=\frac{i}{s}
$$

where $i$ is the current and $s$ is the scan rate. The fabricated supercapacitor shows specific capacitance value of $24 \mathrm{~F} \mathrm{~g} \mathrm{~g}^{-1}$.

The specific capacitance value was further confirmed by complex impedance plot as shown in Figure 7. It was clear that SWCNT electrode materials show capacitive behavior in contact with the GPE, as reflected by the steeply rising behavior of the impedance spectra in the low frequency

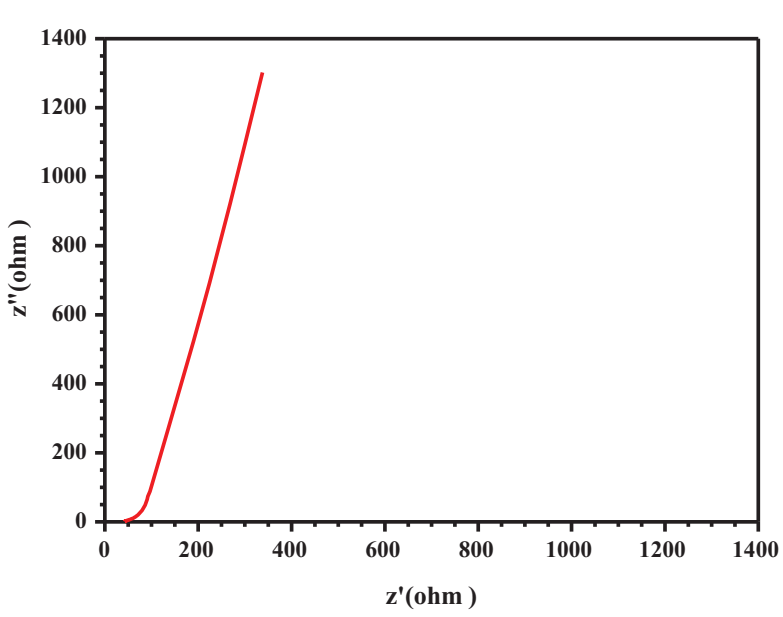

Figure 7. Electrochemical impedance spectra of fabricated EDLC using maximum conductivity ILGPE film and SWCNT electrodes. EDLC: electric double-layer capacitor ILGPE: ionic liquidincorporated gel polymer electrolyte; SWCNT: single-walled carbon nanotube.

range. The values of bulk resistance $\left(R_{\mathrm{b}}\right)$ and interfacial charge-transfer resistance $\left(R_{\mathrm{ct}}\right)$ of EDLC have been evaluated from the intercepts at the real axis of the EIS responses. The value of specific capacitance $(C)$ of EDLC cell was evaluated using the formula,

$$
C=-\frac{1}{\omega \cdot Z^{\prime \prime}} \text { or } C=-\frac{1}{2 \pi f \cdot Z^{\prime \prime}}
$$

where $f$ is the frequency and $Z^{\prime \prime}$ is the imaginary part of the impedance $(Z)$ of the cell, estimated at a low frequency of $10 \mathrm{mHz}$. The EDLC shows $R_{\mathrm{b}}$ of $41 \Omega$ and $R_{\mathrm{ct}}$ of $28 \Omega$ with $C$ value of $28 \mathrm{~F} \mathrm{~g}^{-1}$, which matches well with our $\mathrm{CV}$ data.

The fabricated EDLC has also been tested with galvanostatic charge-discharge method. The typical charge-discharge curve of EDLC is shown in Figure 8. The discharge characteristic has been found to be almost linear, which confirms the capacitive behavior of the EDLC cell. An initial drop in the voltage while discharging the cell has been observed, which is due to the ohmic loss across internal resistance ( $R_{\mathrm{i}}$, also referred to as ESR) of the cells. The internal resistance has been calculated from these voltage drops. The discharge capacitance $\left(C_{\mathrm{d}}\right)$ value has been evaluated from the linear part of the discharge characteristics (Figure 8) using the equation,

$$
C=\mathrm{i} \times \frac{\Delta t}{\Delta V}
$$

where $i$ is the constant current and $\Delta t$ is the time interval for the voltage change of $\Delta V$. The energy density of the cell has also been estimated from the corresponding value of the capacitance by keeping the working voltage $0.8 \mathrm{~V}$, while the power density value has been evaluated by dividing the energy density values with discharge time of the cells. 


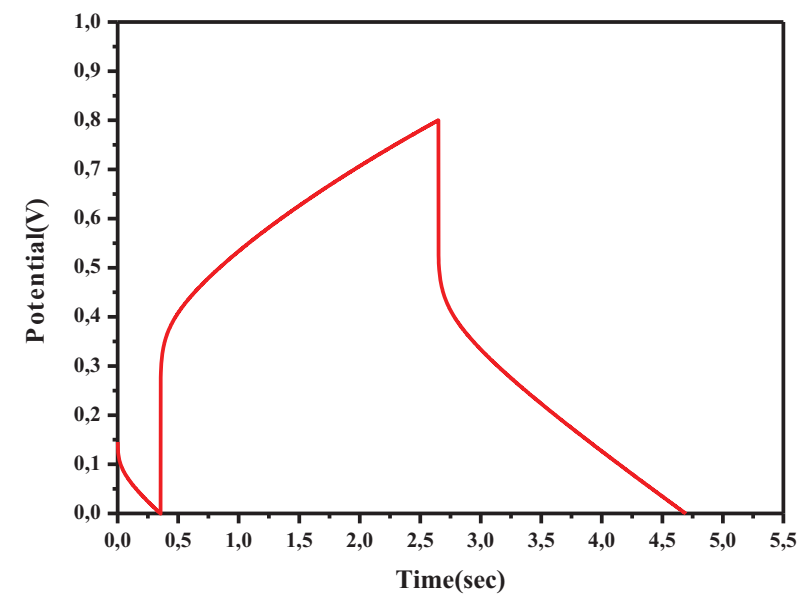

Figure 8. Charge-discharge curve of EDLC. EDLC: electric double-layer capacitor.

Table 2. Typical charge-discharge parameters of EDLC cell at a constant current density of $2.5 \mathrm{~mA} \mathrm{~cm}^{-2}$.

\begin{tabular}{lcccc}
\hline Ri $\left(\Omega \mathrm{cm}^{-2}\right)$ & $C_{\mathrm{d}}\left(\mathrm{F} \mathrm{g}^{-1}\right)$ & $\begin{array}{c}\text { Working } \\
\text { voltage }(\mathrm{V})\end{array}$ & $\begin{array}{c}\text { Energy } \\
\text { density } \\
\left(\mathrm{Wh} \mathrm{kg}^{-1}\right)\end{array}$ & $\begin{array}{c}\text { Power } \\
\text { density } \\
\left(\mathrm{kW} \mathrm{kg}^{-1}\right)\end{array}$ \\
\hline 120 & 25 & 0.8 & 0.31 & 0.26 \\
\hline
\end{tabular}

$C_{\mathrm{d}}$ : discharge capacitance; EDLC: electric double-layer capacitor.

The values of the internal resistance $R_{\mathrm{i}}$, discharge capacitance $C_{\mathrm{d}}$, energy density, and power density of EDLC cell calculated from charge-discharge characteristics are listed in Table 2. All these values are in well agreement with the values obtained from the impedance spectroscopy and CV studies.

\section{Conclusions}

We have fabricated an efficient EDLC using IL-polymer GPE film. The prepared ILGPE films showed high conductivity value in comparison to the pure polymer matrix. ${ }^{38,39}$ The maximum conductivity of ILGPE film was obtained at $250 \mathrm{wt} \%$ of IL composition with a conductivity value of about $10^{-5} \mathrm{~S} \mathrm{~cm}^{-1}$ using EIS. Blending IL in polymer matrix provided additional charge carriers and reduces crystalline matrix of PVA (observed in XRD, DSC, and $\mathrm{OM}$ ), and hence, the conductivity increases. The interaction within the polymer chain and IL ions are confirmed by FTIR spectra. The developed EDLC using SWCNT electrodes and ILGPE (with maximum conductivity composition) further affirms good specific capacitance value (about $28 \mathrm{~F} \mathrm{~g}^{-1}$ ) using $\mathrm{CV}$, complex impedance, and charge-discharge measurements.

\section{Acknowledgement}

The authors would like to thank to Dr Ceylan Zafer for his fruitful discussion.

\section{Declaration of conflicting interests}

The author(s) declared no potential conflicts of interest with respect to the research, authorship, and/or publication of this article.

\section{Funding}

The author(s) disclosed receipt of the following financial support for the research, authorship, and/or publication of this article: This work was supported by TUBITAK fellowship, Government of Turkey.

\section{Reference}

1. Agrawal RC and Pandey GP. Solid polymer electrolytes: material designing and all-solid state battery applications: an overview. J Phys D Appl Phys 2008; 41: 223001.

2. Winter M and Brodd RJ. What are batteries, fuel cells, and supercapacitors. Chem Rev 2004; 104: 4245-4269.

3. Conway BE. Electrochemical supercapacitors: Scientific fundamentals and technological applications. New York: Kluwer-Plenum, 2009.

4. Burke A. Ultracapacitors: why, how, and where is the technology. J Power Sources 2000; 91: 37-50.

5. Kotz R and Carlen M. Principles and applications of electrochemical capacitors. Electrochim Acta 2000; 45: 2483-2498.

6. Aricò AS, Bruce P, Scrosati B, et al. Nanostructured materials for advanced energy conversion and storage devices. Nature Mater 2005; 4: 366-377.

7. Sharma $\mathrm{P}$ and Bhatti TS. A review on electrochemical double-layer capacitors. Energy Convers Manag 2010; 51: 2901-2912.

8. Tamilarasan P and Ramaprabhu S. Graphene based all-solidstate supercapacitors with ionic liquid incorporated polyacrylonitrile electrolyte. Energy 2013; 51: 374-381.

9. Wu XL, Wen T, Guo HL, et al. Biomass-derived sponge-like carbonaceous hydrogels and aerogels for supercapacitors. ACS Nano 2013; 7: 3589-3597.

10. Swu ZS, Sun Y, Tan YZ, et al. Three-dimensional graphene based macro- and mesoporous frameworks for highperformance electrochemical capacitive energy storage. J Am Chem Soc 2012; 134: 19532-19535.

11. Liu WW, Feng YQ, Yan BX, et al. Superior microsupercapacitors based on graphene quantum dots. Adv Funct Mater 2013; 23: 4111-4122.

12. Cheng $Z$ and Jinping L. Carbon nanotube network film directly grown on carbon cloth for high-performance solidstate flexible supercapacitors. Nanotechnology 2014; 25: 035402 .

13. Zheng H, Zhai T, Yu M, et al. TiO2@C core-shell nanowires for high-performance and flexible solid-state supercapacitors. J Mater Chem C 2013; 1: 225-229.

14. Portet C, Yushin G and Gogotsi Y. Electrochemical performance of carbon onions, nanodiamonds, carbon black and multiwalled nanotubes in electrical double layer capacitors. Carbon 2007; 45: 2511-2518. 
15. Chmiola J, Yushin G, Gogotsi Y, et al. Anomalous increase in carbon capacitance at pore sizes less than 1 nanometer. Science 2006; 313: 1760-1763.

16. Pandey GP, Kumar Y and Hashmi SA. Ionic liquid incorporated polymer electrolyte for supercapacitor application. Indian J Chem 2010; 49A: 743-751.

17. Armand M, Endres F, MacFarlane DR, et al. Ionic-liquid materials for the electrochemical challenges of the future. Nat Mater 2009; 8: 621-629.

18. Nanjundiah C, McDevitt SF and Koch VR. Differential capacitance measurements in solvent-free ionic liquids at $\mathrm{Hg}$ and $\mathrm{C}$ interfaces. J Electrochem Soc 1997; 144: 3392-3397.

19. McEwen AB, Ngo HL, Compte KL, et al. Electrochemical properties of imidazolium salt electrolytes for electrochemical capacitor applications. J Electrochem Soc 1999; 146: 1687-1695.

20. Balducci A, Bardi U, Caporali S, et al. Ionic liquids for hybrid supercapacitors. Electrochem Commun 2004; 6: 566-570.

21. Stephan AM. Review on gel polymer electrolytes for lithium batteries. Eur Polym J 2006; 42: 21-42.

22. Sharma $\mathbf{J}$ and Hashmi SA. Magnesium ion transport in poly (ethylene oxide)-based polymer electrolyte containing plastic-crystalline succinonitrile. J Solid State Electrochem 2013; 17: 2283-2291.

23. Gupta RK, Kim HM and Rhee HW. Poly (ethylene oxide): succinonitrile - a polymeric matrix for fast-ion conducting redox-couple solid electrolytes. J Phys D: Appl Phys 2011; 44: 205106.

24. Guirguis OW and Moselhey MTH. Thermal and structural studies of poly (vinyl alcohol) and hydroxypropyl cellulose blends. Natural Sci 2012; 4: 57-67.

25. Chaurasia SK, Singh RK and Chandra S. Structural and transport studies on polymeric membranes of PEO containing ionic liquid EMIM-TY: evidence of complexation. Solid State Ionics 2011; 183: 32-39.

26. Pandey GP and Hashmi SA. Ionic liquid 1-ethyl-3methylimidazolium tetracyanoborate-based gel polymer electrolyte for electrochemical capacitors. J Mater Chem A 2013; 1: 3372-13428.

27. Alarco PJ, Lebdeh YA, Abouimrane A, et al. The plasticcrystalline phase of succinonitrile as a universal matrix for solid-state ionic conductors. Nat Mater 2004; 3: 476-481.
28. Hashmi SA. Supercapacitor: an emerging power source. Natl Acad Sci Lett 2004; 27: 27-46.

29. Kumar Y, Pandey GP and Hashmi SA. Gel polymer electrolyte based electrical double layer capacitors: comparative study with multiwalled carbon nanotubes and activated carbon electrodes. J Phys Chem C 2012; 116: 26118-26127.

30. Liew CW, Ramesh S and Arof AK. Good prospect of ionic liquid based-poly (vinyl alcohol) polymer electrolytes for supercapacitors with excellent electrical, electrochemical and thermal properties. Int J Hydrog Energy 2014; 39: 2953-2963.

31. Nawaz A, Sharif R, Rhee HW, et al. Efficient dye sensitized solar cell and supercapacitor using 1-ethyl 3-methyl imidazolium dicyanamide incorporated PVDF-HFP polymer matrix. J Ind Eng Chem 2016; 33: 381-384.

32. Singh PK, Sabin KC and Chen X. Ionic liquid-solid polymer electrolyte blends for supercapacitor applications. Polym Bull 2016; 73: 255-263.

33. Preechatiwong $\mathrm{W}$ and Schultz JM. Electrical conductivity of poly(ethylene oxide)-alkali metal salt systems and effects of mixed salts and mixed molecular weights. Polymer 1996; 37 : 5109-5116.

34. Peppas NA and Merrill EW. Differential scanning calorimetry of crystalline PVA hydrogels. J Appl Polym Sci 1976; 20: 1457-1465.

35. Vitucci FM, Trequattrini F, Palumbo O, et al. Infrared spectra of bis (trifluoromethanesulfonyl) imide based ionic liquids: experiments and DFT simulations. Vibrat Spectrosc 2014; 74: 81-87.

36. Kiefer J, Fries J and Leipertz A. Experimental vibrational study of imidazolium-based ionic liquids: Raman and infrared spectra of 1-Ethyl-3-methylimidazolium bis (trifluoromethylsulfonyl) mode and 1-Ethyl-3-methylimidazolium Ethylsulfate. Appl Spectrosc 2007; 61: 1306-1311.

37. Chaurasia SK, Singh RK and Chandra S. Ion-polymer and ion-ion interaction in PEO-based polymer electrolytes having complexing salt $\mathrm{LiClO}_{4}$ and /or ionic liquid, [BMIM][PF 6$]$. J Raman Spectrosc 2011; 42: 2168-2172.

38. Woo HJ, Liew CW, Majid SR, et al. Poly( $\varepsilon$-caprolactone)based polymer electrolyte for electrical double-layer capacitors. High Perform Polym 2014; 26: 637-640.

39. Liew CW, Ramesh S and Arof AK. Investigation of ionic liquid-based poly(vinyl alcohol) proton conductor for electrochemical double-layer capacitor. High Perform Polym 2014; 26: 632-636. 